\title{
The effect of an infographic promotion on research dissemination and readership: A randomized controlled trial
}

Simon Huang, MSc*; Lynsey J. Martin, MD, MHPE*; Calvin H. Yeh, MD, $\mathrm{PhD}^{\dagger}$; Alvin Chin, MD, $\mathrm{MSc}^{\ddagger}$; Heather Murray, MD, MSc ${ }^{\S}$; William B. Sanderson, MD ; Rohit Mohindra, MD, MASc ${ }^{* *}$; Teresa M. Chan, MD, MHPE ; Brent Thoma, MD, MA, MSc*

\section{CLINICIAN'S CAPSULE}

What is known about the topic?

Infographics are graphical illustrations of complex ideas that are broadly shared on social media platforms.

What did this study ask?

What is the effect of a social media strategy using infographics on the readership and dissemination of research articles?

What did this study find?

Infographic articles were associated with increased Altmetric scores and abstract views, but not fulltext views.

Why does this study matter to clinicians?

The promotion of articles with infographics may increase awareness and dissemination of research findings among clinicians.

\section{ABSTRACT}

Objective: Journals use social media to increase the awareness of their publications. Infographics show research findings in a concise and visually appealing manner, well suited for dissemination on social media platforms. We hypothesized that infographic abstracts promoted on social media would increase the dissemination and online readership of the parent research articles.

Methods: Twenty-four articles were chosen from the six issues of CJEM published between July 2016 and June 2017 and randomized to infographic or control groups. All articles were disseminated through the journal's social media accounts (Twitter and Facebook). Control articles were promoted using a screen capture image of each article's abstract on the journal's social media accounts. Infographic articles were promoted similarly using a visual infographic.
Infographics were also published and promoted on the CanadiEM.org's website and social media channels. Abstract views, full-text views, and the change in Altmetric score were compared between groups using unpaired two-tailed t-tests. Results: There were no significant differences in the groups at baseline. Abstract views (mean, 95\% Cl) were higher in the infographics $(379,287-471)$ than the control group (176, 136$215, p<0.001)$. Mean change in Altmetric scores was higher in the infographics $(26,18-34)$ than in the control group $(3,2-4$, $p<0.0001)$. There was no difference in full-text views between the infographics $(50,0-101)$ and control groups $(25,18-32)$.

Conclusion: The promotion of CJEM articles using infographics on social media and the CanadiEM.org website increased Altmetric scores and abstract views. Infographics may have a role in increasing awareness of medical literature.

\section{RÉSUMÉ}

Contexte: Les responsables des revues utilisent les médias sociaux pour faire connaître leurs publications. L'infographie permet de présenter des résultats de recherche d'une manière concise et visuellement accrocheuse, moyen bien adapté à la diffusion de connaissances dans les plateformes de médias sociaux. L'étude visait donc à vérifier l'hypothèse selon laquelle la promotion infographique de résumés dans les médias sociaux aurait pour effet d'accroître la diffusion ainsi que le nombre de cyberlecteurs des articles maîtres en version intégrale.

Méthode: Ont été choisis 24 articles tirés des 6 numéros de la revue Canadian Journal of Emergency Medicine (CJEM) publiés entre juillet 2016 et juin 2017, et répartis au hasard entre le groupe d'infographie et le groupe témoin. Tous les articles ont été diffusés par l'intermédiaire des comptes de médias sociaux (Twitter and Facebook) de la revue. Les articles dans le groupe témoin ont fait l'objet de promotion à I'aide d'une capture d'écran du résumé de chacun des articles

From the *Department of Emergency Medicine, University of Saskatchewan, Saskatoon, SK; †Department of Emergency Medicine, University of Toronto, Toronto, ON; ¥Division of Emergency Medicine, McMaster University, Hamilton, ON; §Department of Emergency Medicine, Queen's University, Kingston, ON; IDepartment of Emergency Medicine, University of Kentucky, Lexington, KY; and; and **Department of Emergency Medicine, Jewish General Hospital, Montreal, QC.

Correspondence to: Dr. Brent Thoma, Room 2646, Box 16, 103 Hospital Drive, Saskatoon, SK S7N 0W8; Email: brent.thoma@usask.ca 
dans les comptes de médias sociaux de la revue. Les articles dans le groupe d'infographie ont fait l'objet d'une promotion comparable, mais à l'aide d'une présentation visuelle assistée par ordinateur, en plus d'être publiés et promotionnés dans le site Web CanadiEM.org et les chaînes de médias sociaux. Le nombre de visionnements des résumés et des articles en version intégrale ainsi que les variations des mesures Altmetric ont aussi été comparés entre les deux groupes à l'aide de tests bilatéraux non appariés.

Résultats: Au départ, il n'y avait pas de différences importantes entre les deux groupes. Toutefois, le nombre de visionnements des résumés (moyenne; IC à $95 \%$ ) était plus élevé dans le groupe d'infographie (379: 287-471) que dans le groupe témoin (176:136-215; $p<0,001)$. Il en allait de même pour les variations moyennes des mesures Altmetric (26:18-
34 dans le groupe d'infographie contre $3: 2-4$ dans le groupe témoin; $p<0,0001)$. Par contre, il n'y avait pas de différence entre les deux groupes (infographie : 50 [0-101]; témoin (25 [18-32]) pour ce qui est du nombre de visionnements des articles en version intégrale.

Conclusion: La promotion des articles de la revue CJEM à I'aide de l'infographie dans les médias sociaux et le site Web CanadiEM.org s'est traduite par une augmentation des mesures Altmetric et du nombre de visionnements des résumés. L'infographie pourrait donc permettre une diffusion accrue de la documentation médicale.

Keywords: infographics, knowledge translation, online educational resources, social media

\section{INTRODUCTION}

With the increased publication of medical literature, ${ }^{1,2}$ it is challenging for clinicians to keep up with new research findings. It has been estimated that it can take up to 17 years for the implementation of new information in clinical practice, ${ }^{3-5}$ but this varies based on the information being evaluated. ${ }^{6}$ Improving the dissemination time of new information to front-line practitioners is one modifiable barrier that can be achieved using emerging social media. ${ }^{7}$

Knowledge translation of the medical literature is the "application of knowledge... to accelerate the capture of the benefits of research." ${ }^{8}$ A critical factor in knowledge translation is "awareness of the literature," defined as having read or knowing that a study or guideline exists. $^{9-12}$ Time constraints and volume of published literature are frequently cited barriers to awareness. ${ }^{9}$ Innovative promotional methods that emphasize brevity and the use of visual cues are a possible solution. ${ }^{7,13}$

Educational research supporting cognitive load theory and dual-coding theory suggests that readers learn and remember the contents of article summaries better if they are presented in a combined written text and graphic formats, rather than text-only formats. ${ }^{14-19}$ Infographics are graphical visualizations of data used to simplify complex ideas and are increasingly used by free open-access medical education websites and social media outlets. ${ }^{13,18,20}$ As they are broadly shared on social media platforms, such as Twitter and Facebook, presenting abstracts in infographic format may improve the dissemination and readership of research articles. ${ }^{7,13}$

Our previous non-randomized study found that social media-based promotion of journal articles with infographics increased abstract viewership and Altmetric scores. ${ }^{7}$ This randomized controlled trial (RCT) compared the impact of a robust social media promotion strategy involving both infographics and collaboration with an external website (CanadiEM.org) with text-only abstracts promoted by the journal alone.

\section{METHODS}

This research study was deemed exempt by the University of Saskatchewan Behavioral Research Ethics Board (BEH 16-407).

\section{Design}

An RCT design was used for this study. Four original research articles were chosen from each issue of CFEM published between July 2016 and June 2017. Other article types, such as editorials and case reports, were excluded from the study. Articles were selected based on their perceived interest to Canadian emergency medicine physicians through a consensus of the study authors (including CFEM's Senior and Junior Social Media Editors and a CFEM editorial team member [HM]). Consensus was achieved via an email-based discussion of the original research articles being published within each issue. The selected articles from each issue were subsequently randomized to intervention (infographic plus CanadiEM.org) and control groups using an online list randomizer (https://www.random.org). Figure 1 outlines the selection process and randomization of articles.

\section{Interventions}

English-language infographics for the intervention group articles were created by medical student and 


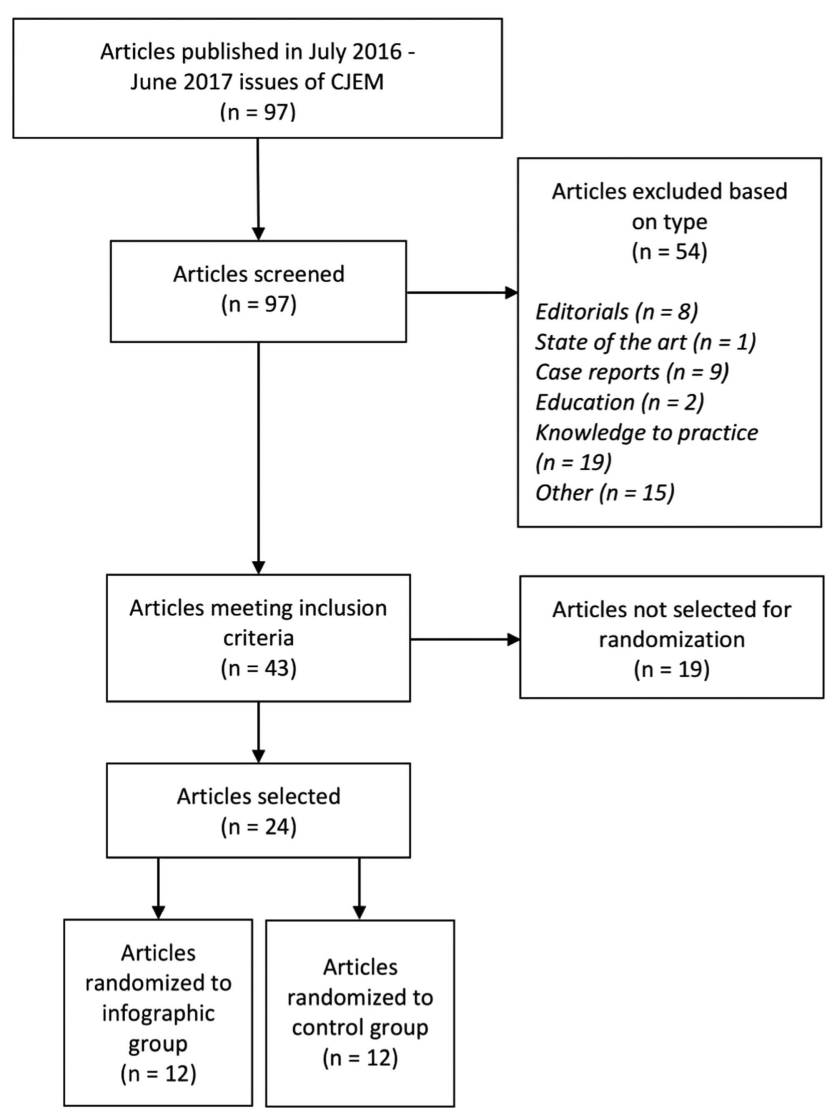

Figure 1. Flow chart outlining CJEM article selection and randomization to infographic and control groups.

resident members of the social media team ( $\mathrm{SH}, \mathrm{CY}$, $\mathrm{AC}, \mathrm{KD}$, and LX). To ensure that the infographics were clear and concise, we adhered to generally accepted principles of design and multimedia learning. In practical terms, we focused on principles of multimedia learning (i.e., coherence, signaling, redundancy, and spatial contiguity $)^{21}$ by minimizing the amount of text, using visual representations when possible, and ensuring that text and graphics were spatially aligned. To achieve the design principles of compellingness and coherence, ${ }^{22}$ each infographic was designed in a way to entice readership (e.g., provocatively phrasing the research question) and to consistently follow the same format between infographics (e.g., introduction, methods, results, and conclusion). ${ }^{22}$ Figure 2 shows an example of one infographic used in our study.

The promotion process for each group is outlined in Figure 3. Infographics were reviewed by all members of the social media promotion team, which included attending emergency physicians with training in both research and education. An informal feedback process

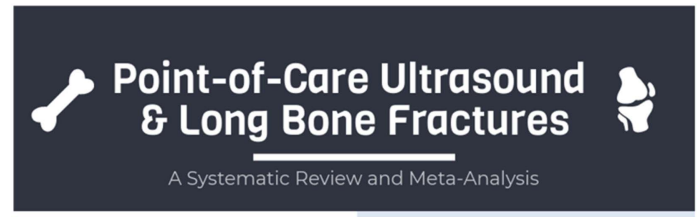

Fractures account for $17 \%$ of injuries in Canadians age $12+$
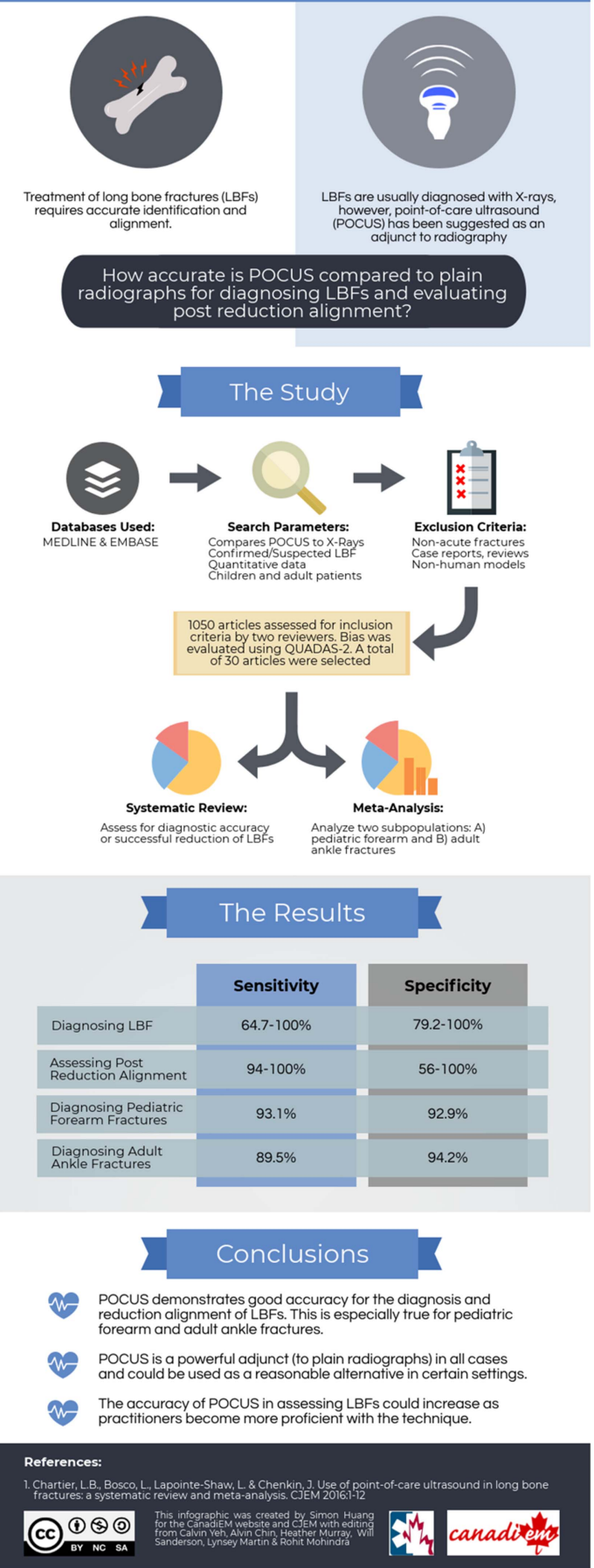

Figure 2. Infographic describing the study "Use of point-ofcare ultrasound in long bone fractures: a systematic review and meta-analysis" that was used in this study. 


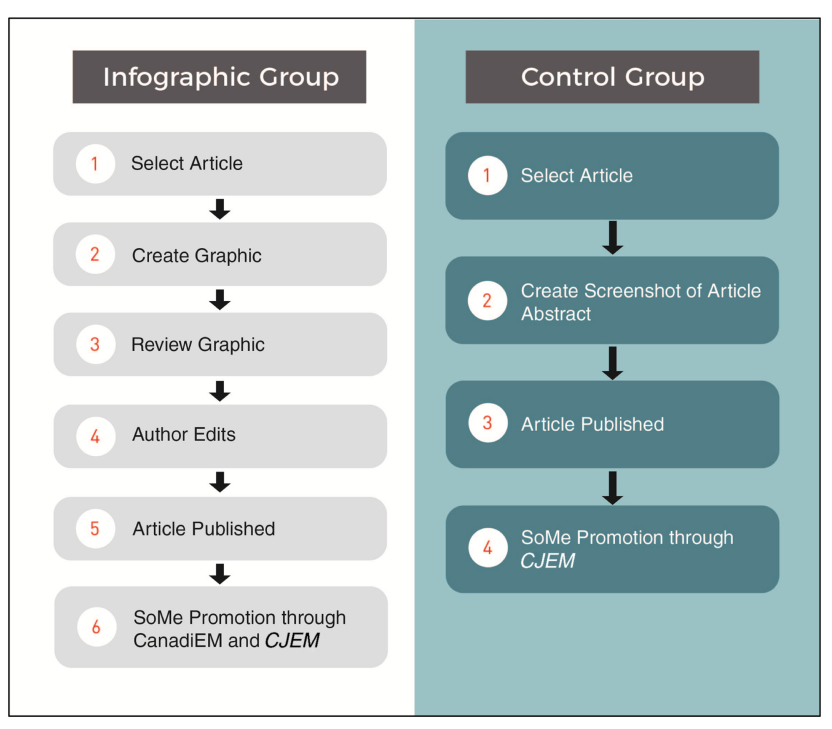

Figure 3. Graphical representation of the social media promotion process for the infographic and control groups.

was used, with content and format edits made based on team suggestions. Each infographic was also reviewed by the article's corresponding authors. For promotion of the control group articles, a screen capture image for each article's text-based abstract was created.

We aimed to promote each article within 1-2 weeks after its official publication in a CFEM issue. All articles had been published online on the CFEM website prior to official publication. Infographic articles were promoted via a 1) tweet of the infographic from both the CFEM and CanadiEM Twitter accounts; 2) post on both the CFEM and CanadiEM Facebook pages; and c) blog-post of the infographic on the CanadiEM website. Control articles were promoted with a tweet from the CFEM Twitter account and post from the CFEM Facebook account that contained a picture of the article's abstract.

\section{Data collection}

Characteristics of the articles in the control and intervention groups were collected to demonstrate comparability between the two groups. They included the mean number of abstract views in the month prior to publication, mean full-text views in the month prior to publication, mean Altmetric score before publication, number of authors, whether the first author was Canadian, and whether the last author was Canadian. Altmetric scores for each article were logged by a member of the study team (SH) prior to each article's print publication date and 30 days following each article's release. Monthly abstract and full-text views for each article were obtained from the journal's publisher (Cambridge University Press).

\section{Outcomes}

The primary outcome of this study was social media dissemination as measured by the change in Altmetric scores between the two groups. Altmetric scores are a freely available proprietary metric that measure the number of times that a journal is referenced by social media such as blogs, podcasts, news media, and other platforms. ${ }^{23}$ The Altmetric score was recorded the day before promotion (infographic or text abstract) and 30 days after promotion to fully capture the effect of social media promotion.

Secondary outcomes included abstract page views (each time the abstract was loaded in a Web browser) and full-text page views (each time the full-text article was loaded in a Web browser or downloaded as a PDF) recorded on the CFEM website in the month of formal publication and the subsequent month. ${ }^{24}$ The 2-month time frame was chosen for the readership metrics to ensure that the full impact of social media promotion was included, because only monthly data were available. Using only the month of publication would have missed increased readership received by an article published and promoted near the end of a month.

\section{Analysis}

Simple descriptive statistics were calculated using Microsoft Excel (2016). Abstract views, full-text views, and the change in Altmetric scores were reported as the mean with $95 \%$ confidence interval (95\% CI). The change in Altmetric score was calculated by subtracting the Altmetric score of each article on the date that the article was formally published from the Altmetric score 30 days later. Unpaired two-tailed t-tests were used to evaluate for the significant differences between the two groups at baseline and following the intervention.

\section{RESULTS}

Tables 1 and 2 show the list of articles in the control and infographic groups, respectively. Descriptive data for the articles in both groups are shown in Table 3. Although infographic articles had slightly higher 


\begin{tabular}{|c|c|c|}
\hline Year & Issue & Article \\
\hline 2016 & July & $\begin{array}{l}\text { "Hands-on defibrillation and electrocardiogram artifact filtering technology increases chest compression fraction and } \\
\text { decreases peri-shock pause duration in a simulation model of cardiac arrest" }\end{array}$ \\
\hline 2016 & July & "Stroke education in Canadian emergency residency programs" \\
\hline 2016 & September & "Reported provision of analgesia to patients with acute abdominal pain in Canadian paediatric emergency departments" \\
\hline 2016 & September & "Impact of phlebotomy tourniquet use on lactate levels in acutely ill patients" \\
\hline 2016 & November & "The effect of a full bladder on proportions of diagnostic ultrasound studies in children with suspected appendicitis" \\
\hline 2016 & November & "Development and evaluations of a simulation-based curriculum for ultrasound-guided central venous catheterization" \\
\hline 2017 & January & $\begin{array}{l}\text { "A cost analysis of salbutamol administration by metered-dose inhalers with spacers vs nebulization for patients with } \\
\text { wheeze in the pediatric emergency department: Evidence from observational data in Nova Scotia" }\end{array}$ \\
\hline 2017 & January & "Validation of the new Vancouver Chest Pain Rule in Asian chest pain patients presenting at the emergency department" \\
\hline 2017 & March & "A retrospective cohort study examining treatments and operative interventions for frostbite in a tertiary care hospital" \\
\hline 2017 & March & $\begin{array}{l}\text { "Did amendments to the Ontario Highway Traffic Act in 2009-2010 affect the proportion of alcohol-related motor vehicle } \\
\text { collisions seen at a Level I trauma centre over a 10-year period?" }\end{array}$ \\
\hline 2017 & May & "Feasibility of emergency department point-of-care ultrasound for rib fracture diagnosis in minor thoracic injury" \\
\hline 2017 & May & $\begin{array}{l}\text { "Iron deficiency anemia in the emergency department: Over-utilization of red blood cell transfusion and infrequent use of } \\
\text { iron supplementation" }\end{array}$ \\
\hline
\end{tabular}

Table 2. List of articles in the infographic group

\begin{tabular}{|c|c|c|}
\hline Year & Issue & Article \\
\hline 2016 & July & "Accuracy of instructor assessment of chest compression quality during simulated resuscitation" \\
\hline 2016 & July & $\begin{array}{l}\text { "Comparison of the Sacco triage method versus START triage using a virtual reality scenario in advance care paramedic } \\
\text { students" }\end{array}$ \\
\hline 2016 & September & $\begin{array}{l}\text { "Does mode of transport confer a mortality benefit in trauma patients? Characteristics and outcomes at an Ontario lead } \\
\text { trauma hospital" }\end{array}$ \\
\hline 2016 & September & "Transient ischemic attack: Management in the emergency department and impact of an outpatient neurovascular clinic" \\
\hline 2016 & November & "Adverse events following diagnostic urethral catheterization in the pediatric emergency department" \\
\hline 2016 & November & $\begin{array}{l}\text { "Bystander fatigue and CPR quality by older bystanders: A randomized crossover trial comparing continuous chest } \\
\text { compressions and 30:2 compressions to ventilations" }\end{array}$ \\
\hline 2017 & January & "Analgesia for acute gingivostomatitis: A national survey of pediatric emergency physicians" \\
\hline 2017 & January & "Prehospital application of the Canadian Triage and Acuity Scale by emergency medical services" \\
\hline 2017 & March & "Use of point-of-care ultrasound in long bone fractures: A systematic review and meta-analysis" \\
\hline 2017 & March & "Predictors of repeated visits to a pediatric emergency department crisis intervention program" \\
\hline 2017 & May & "Antimicrobial treatment decision for non-purulent skin and soft tissue infections in the emergency department" \\
\hline 2017 & May & "Device and medication preferences of Canadian physicians for emergent endotracheal intubation in critically ill patients" \\
\hline
\end{tabular}

abstract views, full-text views, Altmetric scores, and Canadian authors at baseline, these differences were not statistically significant. Furthermore, no significant differences were found between the groups in terms of time to publication or number of authors.

The mean abstract views, mean full-text views, and change in Altmetric scores of each group are presented in Table 4. The infographic group had a significantly larger change in Altmetric score $(p<0.0001)$ and more abstract views $(p<0.001)$ than the control group. There was no statistically significant difference in full-text views.

\section{DISCUSSION}

This study builds on a previously published paper $^{7}$ that outlined the nonrandomized results of CFEM's infographic and podcast-based social media strategy. It reinforces our previous results ${ }^{7}$ by demonstrating the persistence of its findings in a randomized study. It is the first RCT to compare a "standard" medical journal social media strategy of using Facebook and Twitter channels for promotion to a more comprehensive strategy involving infographics created and promoted by a medical education website (https://CanadiEM.org). 
The promotion of articles using infographics

Table 3. Baseline demographic data for articles in the control and infographic groups

\begin{tabular}{lccc}
\hline & Control N (95\% Cl) & Infographic N (95\% Cl) & Difference $(p$ value $)$ \\
\hline Mean abstract views in the month before publication & $21.9(14.9-29.0)$ & $32.3(23.4-41.1)$ & 0.101 \\
Mean full-text views in the month before publication & $2.9(1.7-4.2)$ & $7.1(1.9-12.3)$ & 0.157 \\
Mean Altmetric score before social media promotion & $1.7(0.1-3.2)$ & $3.2(1.2-5.1)$ & 0.26 \\
Mean time between publication and promotion days & $7.3(4.7-9.8)$ & $7.3(4.8-9.7)$ & 1.0 \\
Mean number of authors & $6.3(4.6-7.9)$ & $5.1(4.0-6.2)$ & 0.284 \\
Percentage of Canadian first authors & $83.3(62.2-100.0)$ & 100.0 & 0.152 \\
Percentage of Canadian senior authors & $83.3(62.2-100.0)$ & $91.7(76.0-100.0)$ & 0.557 \\
\hline Cl=confidence interval. & & &
\end{tabular}

Table 4. Comparison of the infographic and control promotional strategies

\begin{tabular}{lccc}
\hline & Control & Infographic & Difference $(p$ value $)$ \\
\hline Abstract views N $(95 \% \mathrm{Cl})$ & $176(136-215)$ & $379(287-471)$ & 0.00601 \\
Full-text views N (95\% Cl) & $25(18-32)$ & $50(0-101)$ & 0.36 \\
Change in Altmetric score N (95\% Cl) & $3(2-4)$ & $26(18-34)$ & 0.000012 \\
$\mathrm{Cl}=$ confidence interval. & & &
\end{tabular}

Similar to the previous study, ${ }^{7}$ full-text readership did not increase despite increased abstract views and dissemination on social media. The reason for the lack of increase in full-text readership is unclear and concerning because this is a primary goal of social media promotion. It is likely that many international readers did not have full-text access to CFEM and were unable to download or view the full article. None of the promoted articles were freely available during the study period; all were behind a pay wall for access. Alternatively, readers may have felt that the infographic was sufficient as a summary and did not feel the need to read the full paper.

The Pathman model for knowledge translation lists four steps in the application of new clinical information: awareness, agreement, adoption, and adherence. ${ }^{11}$ As shown in our study, infographic promotion in collaboration with a medical education website has the potential to raise awareness of an article through increased abstract views and social media dissemination. This is a critical step of knowledge translation, because physicians cannot apply the literature to their practice when they do not know it exists. ${ }^{9-12}$ Unfortunately, awareness is only one of the steps in the knowledge translation pathway. ${ }^{11}$ Physicians often disagree on clinical guidelines and may be caught in the inertia of previous practice. ${ }^{6}$ External factors, such as local practice patterns and resource availability, also contribute as barriers to the adoption of new evidence. ${ }^{6,11}$ Infographic promotion is unlikely to help with these barriers because it is largely limited to increasing awareness.

Infographics require significant time and effort to create. In our study, this process involved a thorough review of the research article, creation of a first draft, and multiple peer reviews for clarity and content. From our experience, we found that an infographic required, on average, 2-3 weeks for production. However, this process was notably longer if author feedback were solicited. We were also fortunate to have experienced infographic editors and peer reviewers as part of the CFEM SoMe team through a collaboration with CanadiEM. Other journals may not have the personnel needed for creating high quality infographics and may need to outsource this work, which could be cost prohibitive, especially if the detailed principles of good design are followed. ${ }^{21,22}$

Visual abstracts are a relatively simpler form of infographic that have recently been adopted by medical journals as a means of summarizing and promoting research articles. ${ }^{13}$ They bear many similarities to the infographics we developed in our study but adhere to a more rigid design. Their brevity and standardization make them considerably easier to create compared to infographics, and they have also been shown to improve dissemination of research on social media platforms. ${ }^{13}$ 
Future studies comparing infographics and visual abstracts would be useful to determine the advantages and disadvantages of each modality.

Overall, our findings support the use of infographics as a valuable knowledge translation tool for the initial phase of increasing awareness. Furthermore, infographic abstracts may provide additional benefit to medical journals by increasing their visibility and presence on social media.

\section{LIMITATIONS}

The promotion of infographic articles on the CanadiEM social media platform may have increased dissemination and makes it impossible to isolate the impact of infographics alone on Altmetric scores and abstract views. The inclusion of a third arm consisting of infographics created and promoted by CFEM alone would be helpful to address this question in future studies.

We were unable to perform a power calculation due to a lack of data from prior studies, and, because of the labour-intensive process of creating infographics, we were limited to a sample size of 24 articles. This may have limited the statistical power to detect a difference in full-text views.

Because only abstract and full-text views from the CFEM website were available for analysis, views and downloads through other means (e.g., PubMed, institutional repositories, and self-archiving) were not included and could have resulted in underestimations of readership. Furthermore, because abstract views and full-text views were available monthly only, readership metrics had to be collected for 2 months, which may have diluted the short-term impact of the infographic.

Free full-text access to articles published in CFEM was limited to members of the Canadian Association of Emergency Physicians (CAEP) or to academic institutions with access to Cambridge journals. Many readers may have had limited access to the articles in this study, as a result. This likely limited the full-text views in both groups; however, given the difference in Altmetric scores, it would likely have had a greater impact on the intervention group. This would have decreased the likelihood of finding a significant increase in fulltext views.

Finally, emergency medicine has an established virtual community of practice that may not exist in other fields of medicine, ${ }^{25,26}$ and we used a prominent social media platform in the CanadiEM website to disseminate the infographics online. These conditions may decrease the likelihood that journals in other fields of medicine are able to replicate the results of this study.

\section{CONCLUSIONS}

$C 7 E M$ articles that promoted using infographics in collaboration with a medical education website had higher abstract viewership and Altmetric scores than those promoted with traditional social media methods. Based on these results, we believe that infographic abstracts are a tool that medical journals and researchers can use to effectively promote their research findings and increase their visibility on social media. The lack of a significant increase in full-text readership is concerning and suggests that the promoted articles were unlikely to be read in detail.

\section{SUPPLEMENTARY MATERIALS}

For supplementary material/s referred to in this article, please visit https://doi.org/10.1017/cem.2018.436

Competing interests: Simon Huang, Calvin H. Yeh, Alvin Chin, Heather Murray, Teresa M. Chan, and Brent Thoma are editors and/or advisory board members of the CanadiEM website.

\section{REFERENCES}

1. Bornmann L, Mutz R. Growth rates of modern science: a bibliometric analysis based on the number of publications and cited references. 7 Assoc Inf Sci Technol 2015;66 (11):2215-22.

2. Druss BG, Marcus SC. Growth and decentralization of the medical literature: implications for evidence-based medicine. 7 Med Libr Assoc 2005;93(4):499-501.

3. Morris ZS, Wooding S, Grant J, Med JRS. The answer is 17 years, what is the question: understanding time lags in translational research. $7 R$ Soc Med 2011;104(12):510-20.

4. Balas EA, Boren SA. Managing clinical knowledge for health care improvement. Yearb Med Inform 2000;9(1):65-70. http://augusta.openrepository.com/augusta/handle/10675.2/ 617990

5. Grant J, Green L, Mason B. Basic research and health: a reassessment of the scientific basis for the support of biomedical science. Res Eval 2003;12(3):217-24.

6. Cabana MD, Rand CS, Powe NR, et al. Why don't physicians follow clinical practice guidelines? A framework for improvement. FAMA 1999;282(15):1458-65.

7. Thoma B, Murray H, Huang SYM, et al. The impact of social media promotion with infographics and podcasts on research dissemination and readership. CFEM 2018;20(2):300-6. 
8. Graham ID, Logan J, Harrison MB, et al. Lost in knowledge translation: time for a map? 7 Contin Educ Health Prof 2006;26(1):13-24.

9. Masic I, Miokovic M, Muhamedagic B. Evidence-based medicine - new approaches and challenges. Acta Inform Medica 2008;16(4):219-25.

10. Glasziou P, Haynes B. The paths from research to improved health outcomes. Evid Based Nurs 2005;8(2):36-8.

11. Pathman DE, Konrad TR, Freed GL, et al. The awarenessto-adherence model of the steps to clinical guideline compliance: the case of pediatric vaccine recommendations. Med Care 1996;34(9):873-89.

12. Wimpenny $\mathrm{P}$, Johnson $\mathrm{N}$, Walter I, Wilkinson JE. Tracing and identifying the impact of evidence - use of a modified pipeline model. Worldviews Evid Based Nurs 2008;5 (1):3-12

13. Ibrahim AM, Lillemoe KD, Klingensmith ME, Dimick JB. Visual abstracts to disseminate research on social media: a prospective, case-control crossover study. Ann Surg 2017;266(6):e46-8.

14. Mayer RE, Bove W, Bryman A, et al. When less is more: meaningful learning from visual and verbal summaries of science textbook lessons. 7 Educ Psychol 1996;88(1):64-73.

15. Peeck J. Increasing picture effects in learning from illustrated text. Learn Instr 1993;3(3):227-38.

16. Van Merriënboer JJG, Sweller J. Cognitive load theory in health professional education: design principles and strategies. Med Educ 2010;44(1):85-93.

17. Paivio A, Csapo K. Picture superiority in free recall: imagery or dual coding? Cogn Psychol 1973;5(2):176-206.
18. Dur BIU. Analysis of data visualizations in daily newspapers in terms of graphic design. Procedia Soc Bebav Sci 2012;51 (Figures 1):278-83.

19. Martin LJ, Turnquist A, Groot B, et al. Exploring the role of infographics for summarizing medical literature; 2018. Available at: http://linkinghub.elsevier.com/retrieve/pii /S2452301117300792 (accessed 21 March 2018).

20. Smiciklas M. The power of infographics: using pictures to communicate and connect with your audience. Indianapolis, IN: Que; 2012.

21. Mayer RE, Fiorella L. Principles for reducing extraneous processing in multimedia learning: coherence, signaling, redundancy, spatial contiguity, and temporal contiguity principles. In Mayer RE (ed.) The Cambridge handbook of multimedia learning. 2nd ed. New York: Cambridge University Press; 2014, 279-315.

22. Dunlap JC, Lowenthal PR. Getting graphic about infographics: design lessons learned from popular infographics. $\mathcal{F}$ Vis Lit 2016;35(1):42-59.

23. Trueger NS, Thoma B, Hsu CH, et al. The altmetric score: a new measure for article-level dissemination and impact. Ann Emerg Med 2015;66(5):549-53.

24. Page View. Wikipedia. Available at: http://en.wikipedia.org/ wiki/Page_view (accessed 15 March 2018).

25. Thoma B, Paddock M, Purdy E, et al. Leveraging a virtual community of practice to participate in a survey-based study: a description of the METRIQ study methodology. AEM Educ Train 2017;1(2):110-3.

26. Wenger E, McDermott R, Snyder WM. Cultivating communities of practice: a guide to managing knowledge. Boston, MA: Harvard Business School Press; 2002. 